\title{
An anionic nanotubular metal-organic framework for high-capacity dye adsorption and dye degradation in darkness
}

Shu-Qi Deng, Yi-Ling Miao, Yu-Ling Tan, Hong-Nan Fang, Yue-Ting Li, Xiao-Jing Mo, Song-Liang Cai, * Jun Fan, Wei-Guang Zhang and Sheng-Run Zheng*

School of Chemistry, South China Normal University, Guangzhou, 510006, P. R. China

* Corresponding author: Dr. Song-Liang Cai; Dr. Sheng-Run, Zheng

E-mail address: zhengsr@scnu.edu.cn (S. R. Zheng); songliangcai@m.scnu.edu.cn (S.

L. Cai)

Tel./Fax.: +86-20-39310187 


\section{Supporting Information}

Table S1 Crystallographic data and structure refinement summary for SCNU-Z2

\begin{tabular}{|c|c|}
\hline Complex & SCNU-Z2* \\
\hline Empirical formula & $\mathrm{C}_{16.50} \mathrm{H}_{9} \mathrm{CoN}_{15}$ \\
\hline Formula weight & 476.32 \\
\hline Crystal system & hexagonal \\
\hline Space group & $P 63 / \mathrm{m}$ \\
\hline $\mathrm{a} / \AA$ & $18.387(2)$ \\
\hline $\mathrm{b} / \AA$ & $18.387(2)$ \\
\hline $\mathrm{c} / \AA$ & $14.1407(16)$ \\
\hline$\alpha / \circ$ & 90 \\
\hline$\beta / \circ$ & 90 \\
\hline$\gamma /{ }^{\circ}$ & 120 \\
\hline $\mathrm{V} / \AA^{3}$ & $4140.2(10)$ \\
\hline Z & 4 \\
\hline $\mathrm{D} / \mathrm{g} \mathrm{cm}^{-3}$ & 0.767 \\
\hline$\mu / \mathrm{mm}^{-1}$ & 0.435 \\
\hline $\mathrm{T} / \mathrm{K}$ & $100.00(10)$ \\
\hline$R^{a} / w R^{b}$ & $0.0990 / 0.2114$ \\
\hline Total / unique & 8413 / 3421 \\
\hline Rint & 0.1050 \\
\hline
\end{tabular}

Table S2 Selected bond lengths $[\AA]$ and angles $\left[{ }^{\circ}\right]$ for SCNU-Z2

SCNU-Z2

\begin{tabular}{lrlr}
\hline $\mathrm{Co}(1)-\mathrm{N}(6) \# 1$ & $2.122(4)$ & $\mathrm{Co}(1)-\mathrm{N}(2) \# 4$ & $2.136(4)$ \\
$\mathrm{Co}(1)-\mathrm{N}(6) \# 2$ & $2.122(4)$ & $\mathrm{Co}(1)-\mathrm{N}(2) \# 5$ & $2.136(4)$ \\
$\mathrm{Co}(1)-\mathrm{N}(6) \# 3$ & $2.122(4)$ & $\mathrm{Co}(1)-\mathrm{N}(2)$ & $2.136(4)$ \\
$\mathrm{N}(6) \# 1-\mathrm{Co}(1)-\mathrm{N}(6) \# 2$ & $93.00(13)$ & $\mathrm{N}(6) \# 3-\mathrm{Co}(1)-\mathrm{N}(2) \# 5$ & $88.79(14)$ \\
$\mathrm{N}(6) \# 1-\mathrm{Co}(1)-\mathrm{N}(6) \# 3$ & $93.00(13)$ & $\mathrm{N}(2) \# 4-\mathrm{Co}(1)-\mathrm{N}(2) \# 5$ & $89.29(14)$ \\
$\mathrm{N}(6) \# 2-\mathrm{Co}(1)-\mathrm{N}(6) \# 3$ & $93.00(13)$ & $\mathrm{N}(6) \# 1-\mathrm{Co}(1)-\mathrm{N}(2)$ & $177.35(14)$ \\
$\mathrm{N}(6) \# 1-\mathrm{Co}(1)-\mathrm{N}(2) \# 4$ & $88.79(14)$ & $\mathrm{N}(6) \# 2-\mathrm{Co}(1)-\mathrm{N}(2)$ & $88.79(14)$ \\
$\mathrm{N}(6) \# 2-\mathrm{Co}(1)-\mathrm{N}(2) \# 4$ & $88.87(14)$ & $\mathrm{N}(6) \# 3-\mathrm{Co}(1)-\mathrm{N}(2)$ & $88.87(14)$ \\
$\mathrm{N}(6) \# 3-\mathrm{Co}(1)-\mathrm{N}(2) \# 4$ & $177.35(14)$ & $\mathrm{N}(2) \# 4-\mathrm{Co}(1)-\mathrm{N}(2)$ & $89.29(14)$
\end{tabular}


Symmetry transformations used to generate equivalent atoms: $\# 1 \mathrm{x}-\mathrm{y}+1, \mathrm{x},-\mathrm{z}, \# 2 \mathrm{y},-\mathrm{x}+\mathrm{y},-\mathrm{z}$, $\# 3-x+1,-y+1,-z, \# 4-y+1, x-y, z, \# 5-x+y+1,-x+1, z$.

Table S3 The size and charge of the selected five dyes

\begin{tabular}{|c|c|c|c|c|c|}
\hline \multirow[b]{2}{*}{ Name } & \multicolumn{3}{|c|}{ Cationic } & \multicolumn{2}{|c|}{ Anionic } \\
\hline & MLB & $\mathrm{CV}$ & $\mathrm{RhB}$ & MO & $\mathrm{AO}$ \\
\hline \multicolumn{6}{|c|}{$\begin{array}{l}\text { Structural } \\
\text { formula }\end{array}$} \\
\hline Charge & +1 & +1 & +1 & -1 & -1 \\
\hline$x(\AA)$ & 1.8 & 3.5 & 6.8 & 4.5 & 4.8 \\
\hline $\mathrm{y}(\AA)$ & 5.5 & 13.0 & 11.8 & 6.0 & 7.8 \\
\hline$z(\AA)$ & 14.2 & 13.7 & 15.8 & 14.8 & 12.4 \\
\hline
\end{tabular}




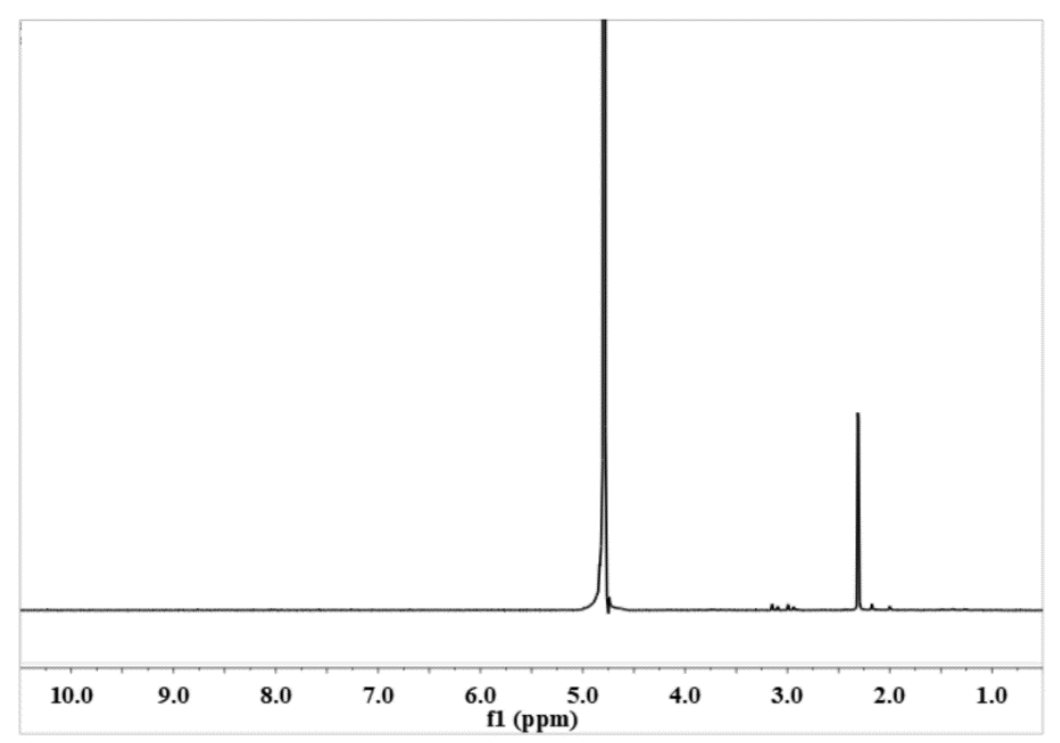

Figure S1. The ${ }^{1} \mathrm{HNMR}$ spectrum of the sodium chloride solution after soaking SCNUZ2.

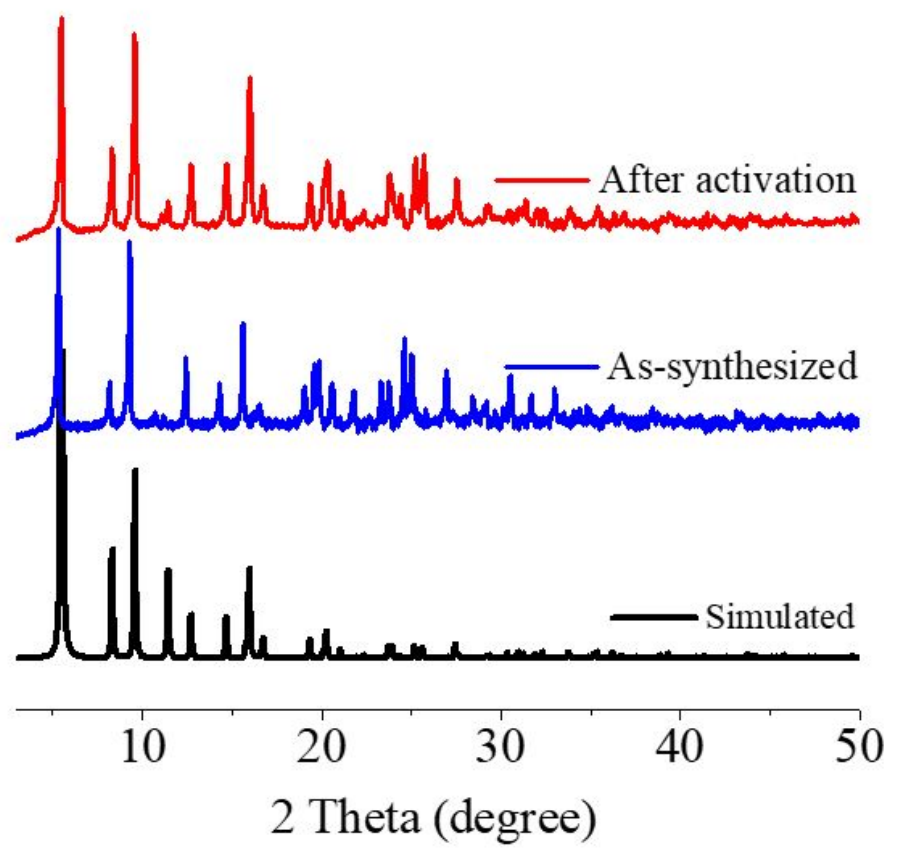

Figure S2. The PXRD patterns of simulated, as-synthesized and activated SCNU-Z2. 


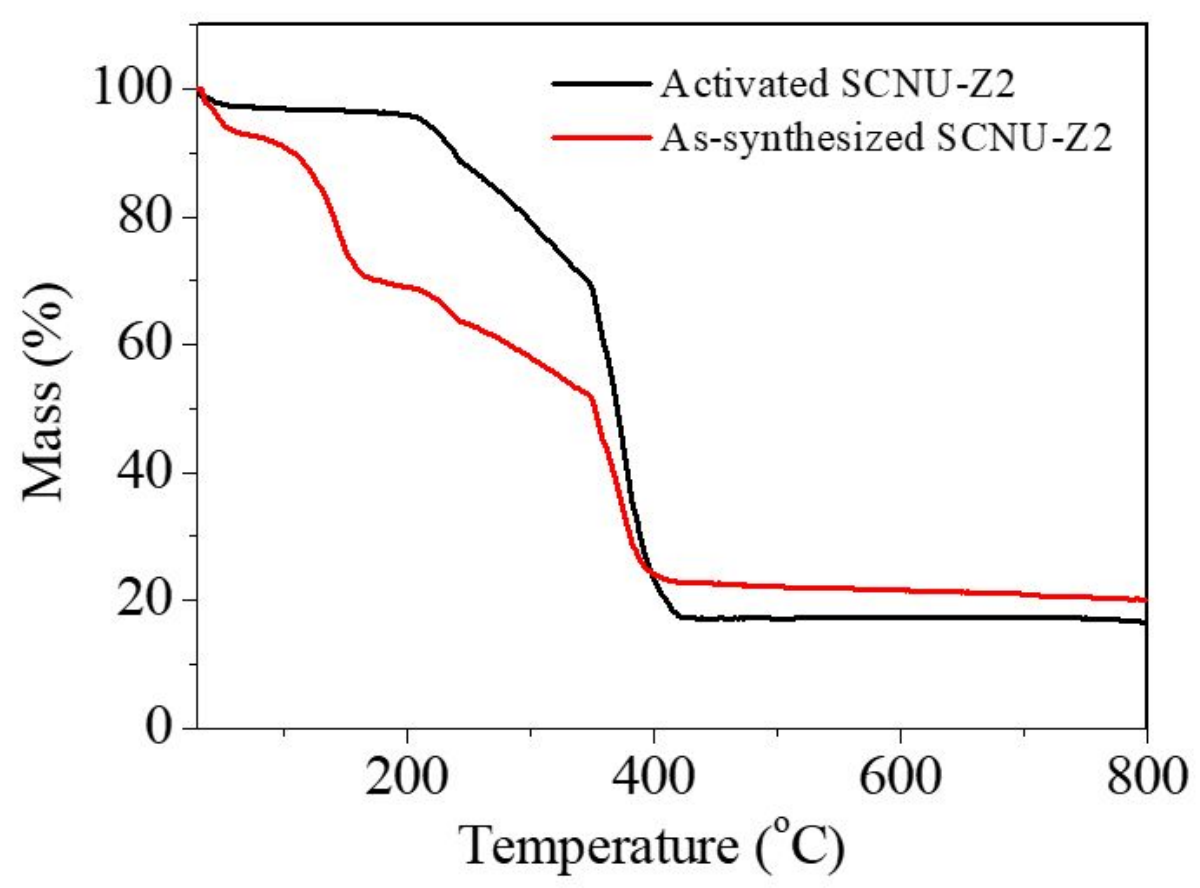

Figure S3. The TG curve of as-synthesized SCNU-Z2, activated SCNU-Z2, assynthesized SCNU-Z2@ $\mathrm{CoCl}_{2}$, activated SCNU-Z2@ $\mathrm{CoCl}_{2}$.

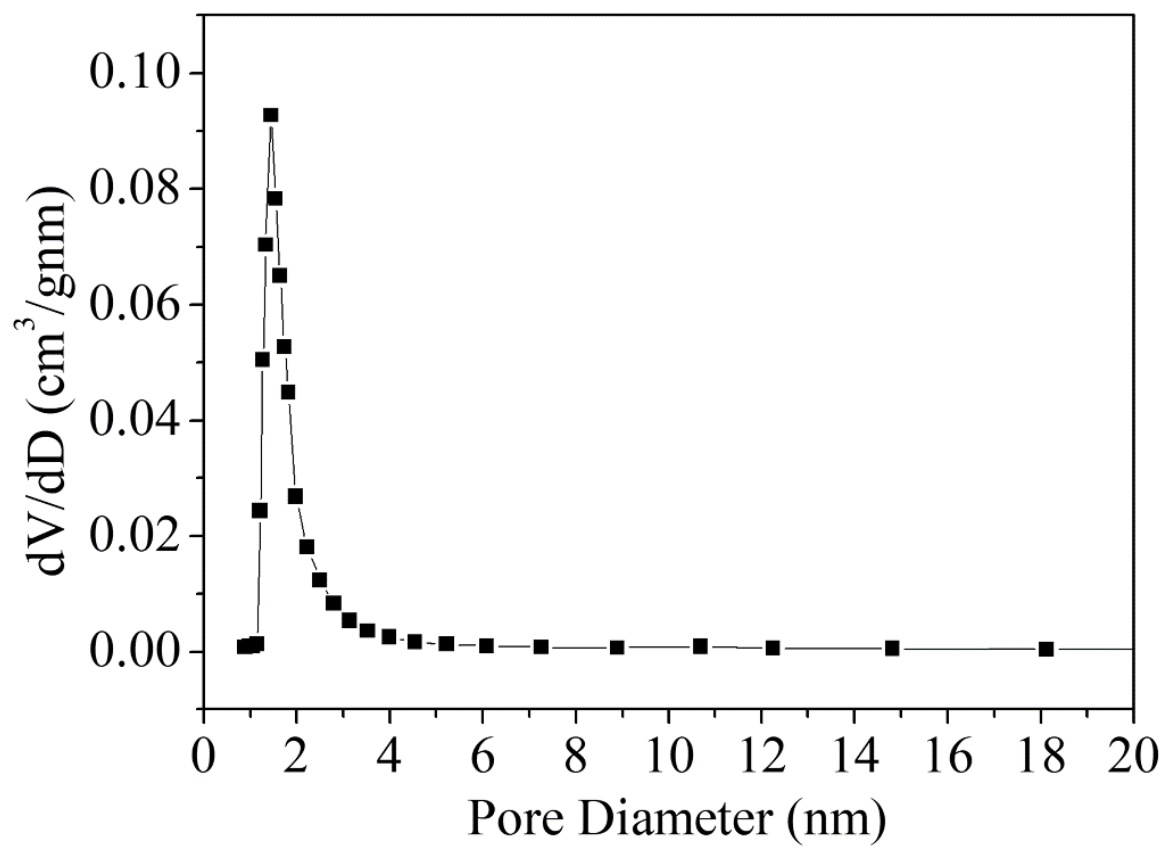

Figure S4. The pore size distributions of SCNU-Z2. 


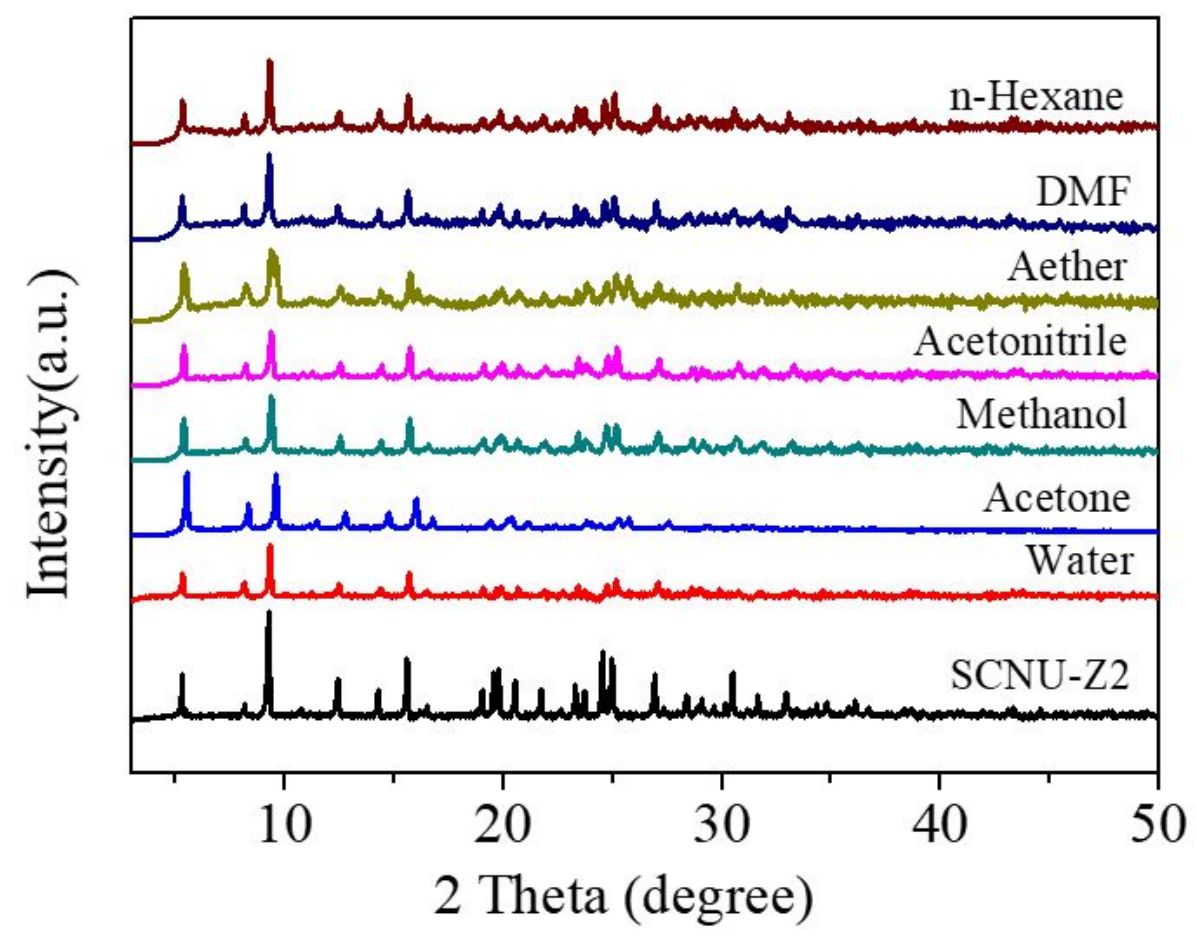

Figure S5. The PXRD of SCNU-Z2 crystals immersed in various solvents after $30 \mathrm{~h}$.

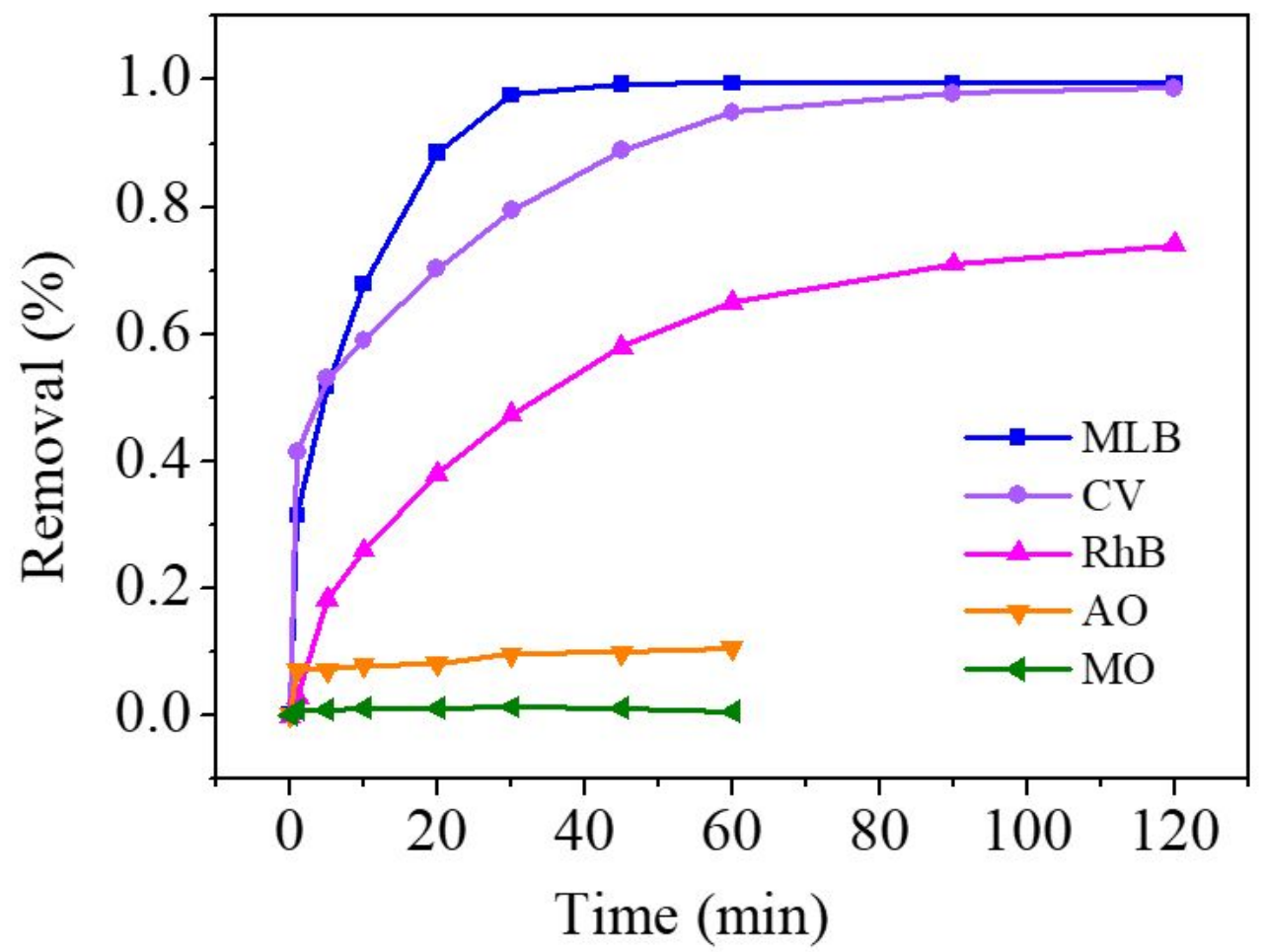

Figure S6. The removal rate of SCNU-Z2 with time for the selected five dyes. 


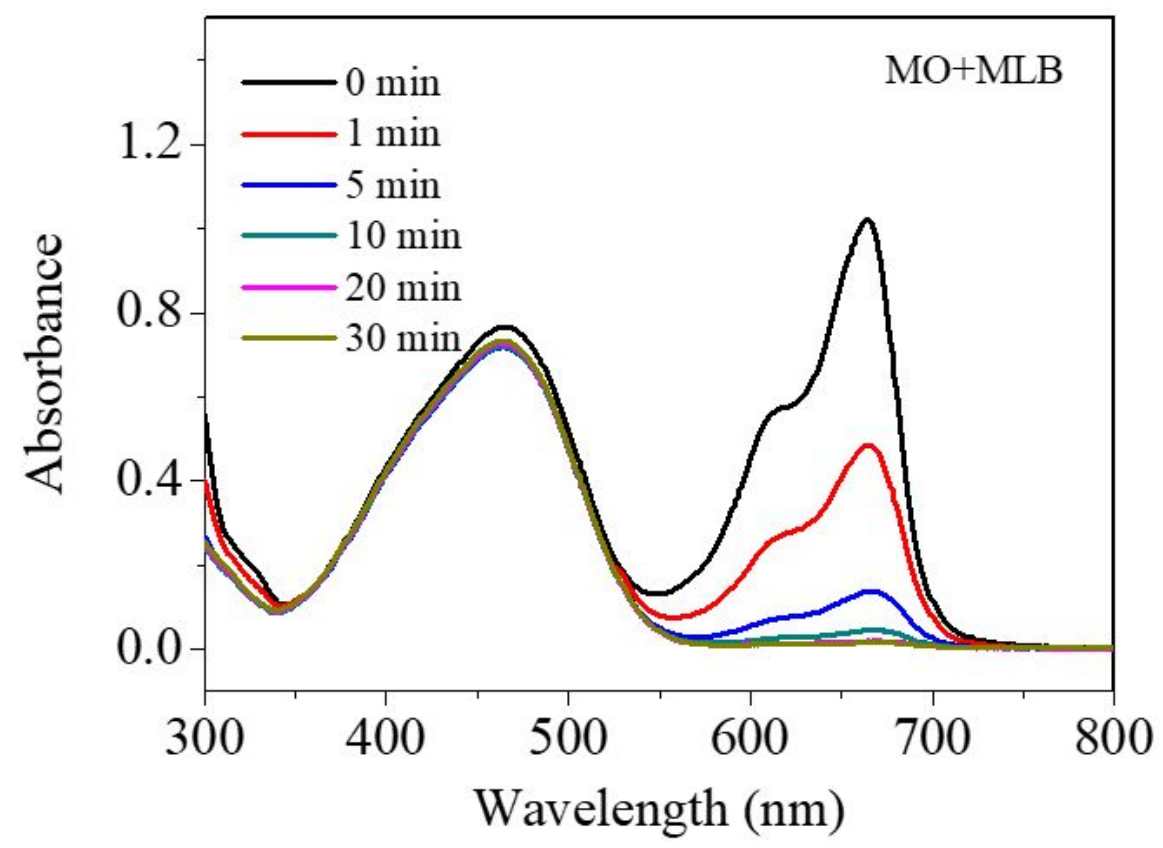

Figure S7. The UV-Vis adsorption spectra of aqueous solution of mixed MLB and MO at different given time.

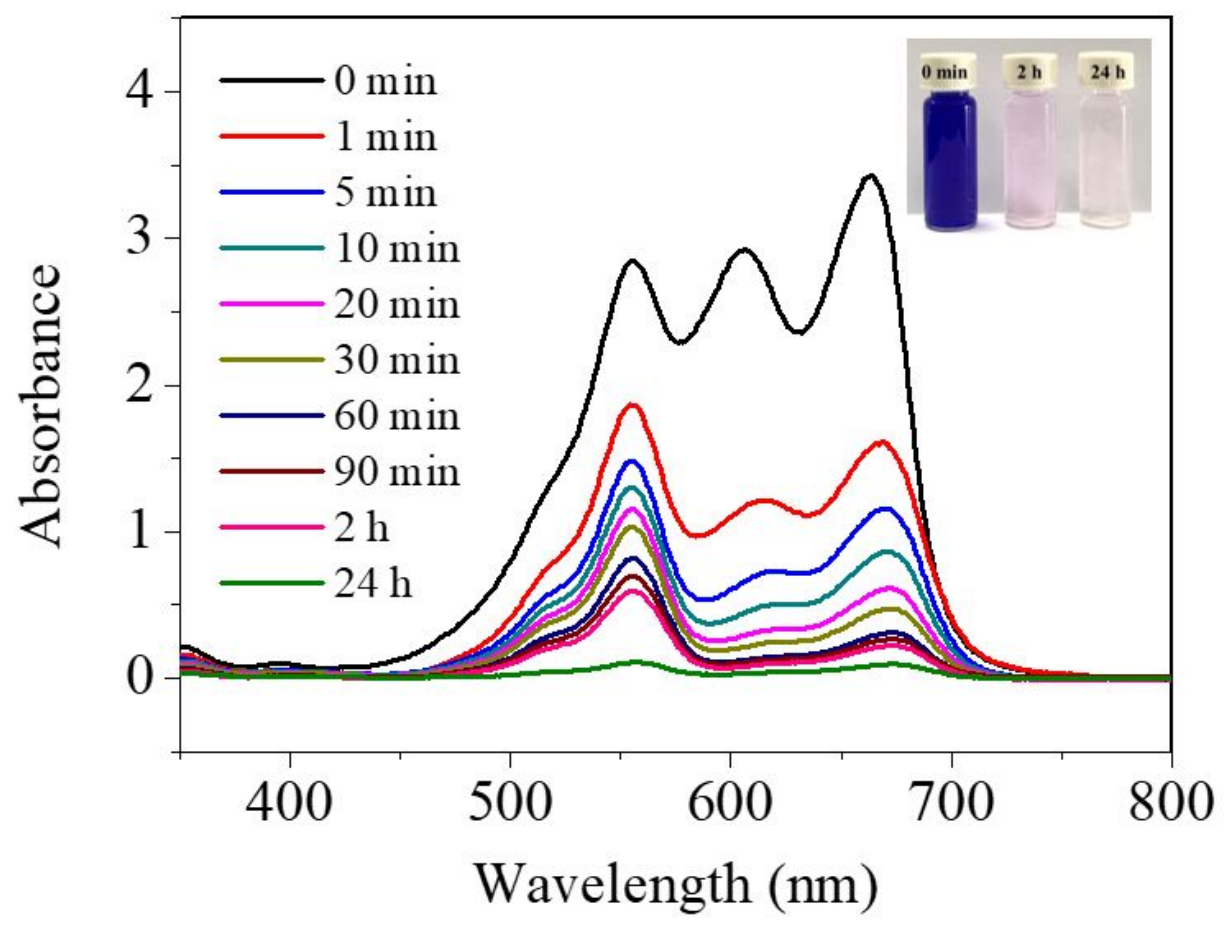

Figure S8. The UV-Vis adsorption spectra of sewage containing MLB, MV and RhB at different given time. 


\section{Adsorption kinetics study.}

The adsorption data were studied using a pseudo-second-order equation, which is shown below:

$\mathrm{t} / \mathrm{Q}_{\mathrm{t}}=1 /\left(\mathrm{k}_{2} \mathrm{Q}_{\mathrm{e}}^{2}\right)+\mathrm{t} / \mathrm{Q}_{\mathrm{e}}$

where $\mathrm{k}_{2}$ is the pseudo-second-order rate constant $(\mathrm{mg} / \mathrm{g} \cdot \mathrm{min}), \mathrm{Q}_{\mathrm{e}}$ and $\mathrm{Q}_{\mathrm{t}}$ are the adsorption capacity at equilibrium and at the time of $t$, respectively.

\section{Adsorption isotherms study.}

Furthermore, the Langmuir, Freundlich and Themkin equations were selected to fit the data.

Langmuir model is the most widely used model based on the assumption of a monolayer adsorption on a homogeneous surface. It can be given by:

$\frac{\mathrm{c}_{\mathrm{e}}}{\mathrm{Q}_{\mathrm{e}}}=\frac{1}{\mathrm{Q}_{\mathrm{m}} \mathrm{b}}+\frac{\mathrm{C}_{\mathrm{e}}}{\mathrm{Q}_{\mathrm{m}}}$

where $c_{e}\left(\mathrm{mg} \mathrm{L}^{-1}\right)$ is the equilibrium concentration of $\mathrm{MB}$ in solution, $\mathrm{Q}_{\mathrm{e}}\left(\mathrm{mg} \mathrm{g}^{-1}\right)$ is the adsorption capacity at equilibrium, $\mathrm{Q}_{\mathrm{m}}\left(\mathrm{mg} \mathrm{g}^{-1}\right)$ and $\mathrm{b}\left(\mathrm{L} \mathrm{mg}^{-1}\right)$ represent the maximum adsorption capacity of adsorbents and the energy of adsorption, respectively.

Freundlich model is another widely applied isothermal model based on the assumption that adsorption energy decays exponentially with coverage rise. The Freundlich equation is given as:

$\operatorname{lnq} Q_{e}=\ln k_{F}+\frac{1}{n} \ln c_{e}$

where $k_{F}\left[\left(\mathrm{mg} \mathrm{g}^{-1}\right)\left(\mathrm{L} \mathrm{mg}^{-1}\right)^{1 / n}\right]$ is a constant indicative of the adsorption capacity of the adsorbent and $(1 / n)$ of the adsorption intensity.

Tempkin model is a widely used isothermal model based on the assumption that adsorption energy decreases linearly with coverage rise. The Tempkin equation is given as:

$\mathrm{Q}_{\mathrm{e}}=\mathrm{B} \ln (\mathrm{A})+\mathrm{Bln}_{\mathrm{e}}$

where $B=(R T / b)$ is related to the heat of adsorption, $A$ is the equilibrium binding constant, $T(\mathrm{~K})$ is the absolute temperature and $R$ is the universal gas constant. 

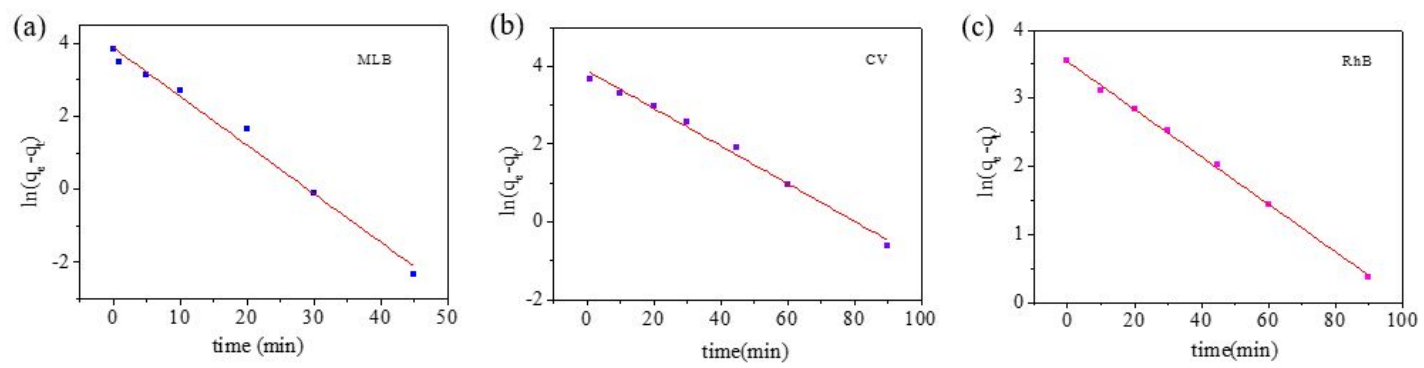

Figure S9. Plot of the pseudo-first-order kinetic model for (a) MLB, (b) CV and (c) $\mathrm{RhB}$ on SCNU-Z2.
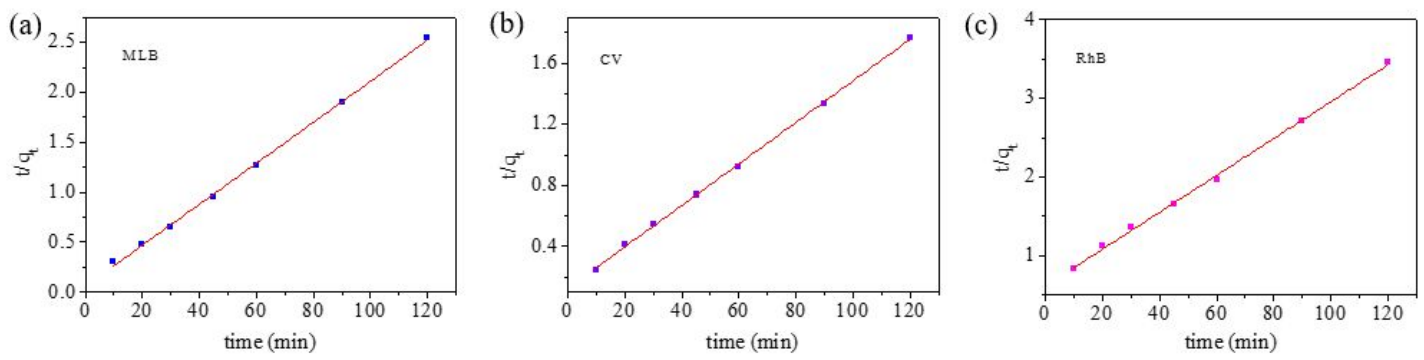

Figure S10. Plot of the pseudo-second-order kinetic model for (a) MLB, (b) CV and (c) RhB on SCNU-Z2.

Table S4 The equilibrium capacities, rate constant and correlation coefficient $\mathrm{R}^{2}$ of SCNU-Z2 adsorbing dyes.

\begin{tabular}{lllll}
\hline & & \multicolumn{3}{l}{ Dyes } \\
\cline { 3 - 5 } & & MLB & CV & RhB \\
\hline \multirow{3}{*}{ Pseudo-first-order } & $\mathrm{q}_{\mathrm{e}, \text { Exp }}(\mathrm{mg} \cdot \mathrm{g}-1)$ & 49.64 & 59.38 & 34.22 \\
& $\mathrm{q}_{\mathrm{e}, \text { Cal }}(\mathrm{mg} \cdot \mathrm{g}-1)$ & 34.57 & 39.77 & 31.03 \\
& $k_{1}\left(\mathrm{~min}^{-1}\right)$ & 0.0319 & 0.0512 & 0.0211 \\
& $\mathrm{R}^{2}$ & 0.9759 & 0.9946 & 0.9951 \\
\hline \multirow{3}{*}{ Pseudo-second-order } & $\mathrm{q}_{\mathrm{e}, \text { Cal }}\left(\mathrm{mg}^{-} \mathrm{g}-1\right)$ & 55.01 & 62.31 & 46.27 \\
& $k_{2}\left(\mathrm{~g} \cdot \mathrm{mg}^{-1} \cdot \mathrm{min}^{-1}\right)$ & 0.0017 & 0.0030 & 0.0009 \\
& $\mathrm{R}^{2}$ & 0.9974 & 0.9997 & 0.9850 \\
\hline
\end{tabular}

Table S5 Accuracy validation of the kinetic models

\begin{tabular}{|c|c|c|c|c|c|c|c|}
\hline \multicolumn{4}{|c|}{ Pseudo-first-order } & \multicolumn{4}{|c|}{ Pseudo-second-order } \\
\hline $\begin{array}{l}\mathrm{q}_{\mathrm{e}, \mathrm{Cal}} \\
\left(\mathrm{mg} \cdot \mathrm{g}^{-1}\right)\end{array}$ & $\begin{array}{l}\text { Mean } \pm S D \text {, } \\
\text { RSD }\end{array}$ & $\begin{array}{l}\mathrm{k}_{1} \\
\left(\min ^{-1}\right)\end{array}$ & $\begin{array}{l}\text { Mean } \pm S D \text {, } \\
\text { RSD }\end{array}$ & $\begin{array}{l}\mathrm{q}_{\mathrm{e}, \mathrm{Cal}} \\
\left(\mathrm{mg} \cdot \mathrm{g}^{-1}\right)\end{array}$ & $\begin{array}{l}\text { Mean } \pm S D \text {, } \\
\text { RSD }\end{array}$ & $\begin{array}{l}\mathrm{k}_{2} \\
\left(\mathrm{~g}^{\prime} \mathrm{mg}^{-1} \cdot \mathrm{min}^{-1}\right)\end{array}$ & $\begin{array}{l}\text { Mean } \pm \text { SD, } \\
\text { RSD }\end{array}$ \\
\hline 30.17 & \multirow{3}{*}{$\begin{array}{l}31.17 \pm 0.90 \\
0.03\end{array}$} & 0.0206 & \multirow{3}{*}{$\begin{array}{l}0.0218 \pm 0.001 \\
0.0398\end{array}$} & 44.92 & \multirow{3}{*}{$\begin{array}{l}46.03 \pm \\
0.03\end{array}$} & 0.0009 & $0.0009 \pm 0.00$ \\
\hline 32.35 & & 0.0227 & & 47.73 & & 0.0009 & 001, \\
\hline 30.99 & & 0.0216 & & 45.43 & & 0.0009 & 0.0145 \\
\hline
\end{tabular}



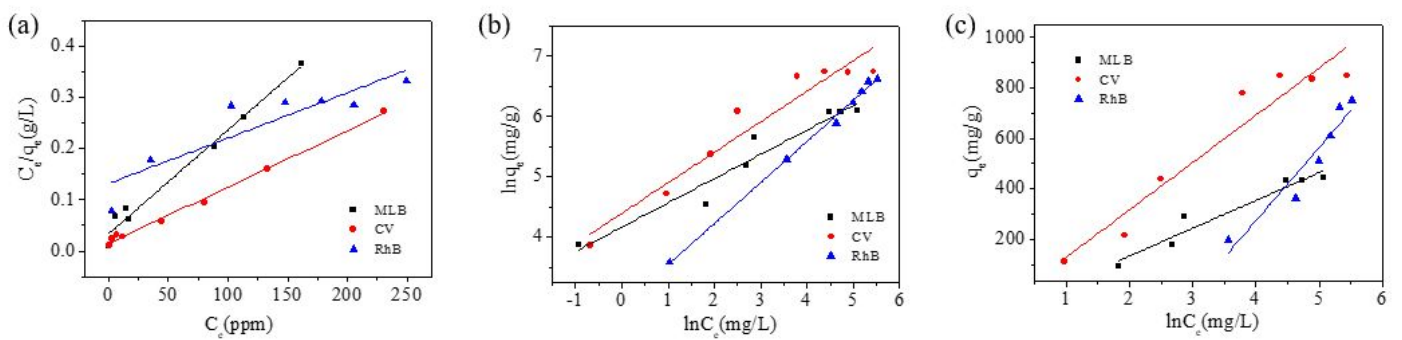

Figure S11. Plots of the fitting of the dyes adsorption experimental data with (a) Langmuir, (b) Freundlich and (c) Tempkin isotherm modes.

Table S6 Parameters of the adsorption of different oxo-anions on SCNU-Z2.

\begin{tabular}{|c|c|c|c|c|}
\hline & & \multicolumn{3}{|c|}{ Dyes } \\
\hline & & MLB & $\mathrm{CV}$ & $\mathrm{RhB}$ \\
\hline \multirow{3}{*}{ Langmuir } & $\mathrm{q}_{\mathrm{m}}\left(\mathrm{mg} \cdot \mathrm{g}^{-1}\right)$ & 492.6 & 909.1 & 1127.5 \\
\hline & $\mathrm{b}\left(\mathrm{L} \cdot \mathrm{mg}^{-1}\right)$ & 0.0606 & 0.0754 & 0.0067 \\
\hline & $\mathrm{R}^{2}$ & 0.9804 & 0.9943 & 0.7690 \\
\hline \multirow{3}{*}{ Freundlich } & $\mathrm{n}$ & 2.4829 & 1.9748 & 1.4697 \\
\hline & $\begin{array}{l}\mathrm{k}_{\mathrm{F}} \quad\left(\mathrm{mg} \quad \mathrm{g}^{-1}\left(\mathrm{~L}^{\prime} \cdot \mathrm{mg}^{-}\right.\right. \\
\left.\left.{ }^{1}\right)^{1 / \mathrm{n}}\right)\end{array}$ & 64.06 & 80.84 & 17.49 \\
\hline & $\mathrm{R}^{2}$ & 0.9251 & 0.9231 & 0.9956 \\
\hline \multirow{2}{*}{ Tempkin } & $\mathrm{A}\left(\mathrm{L} \cdot \mathrm{g}^{-1}\right)$ & 0.4546 & 0.7361 & 0.0471 \\
\hline & B & 110.16 & 187.21 & 289.69 \\
\hline
\end{tabular}


(a)

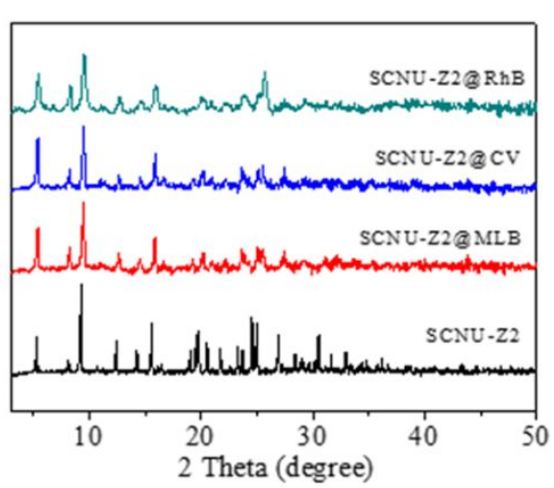

(c)

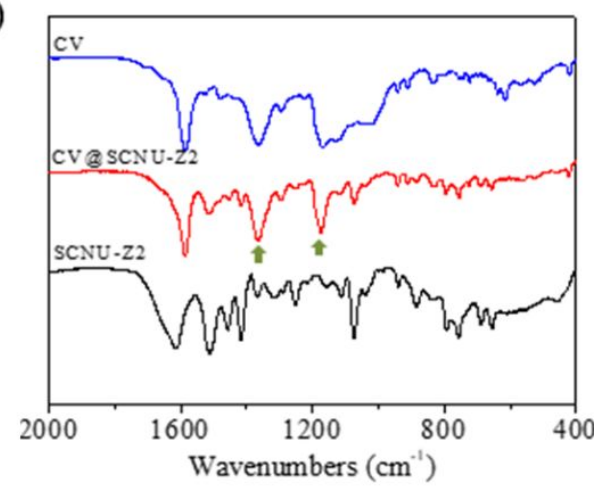

(b)

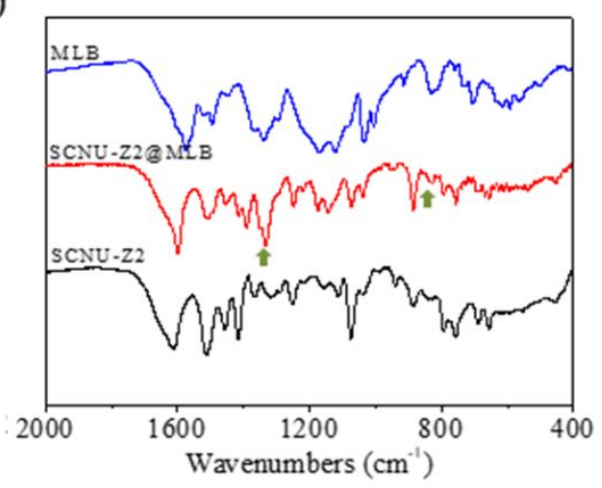

(d)

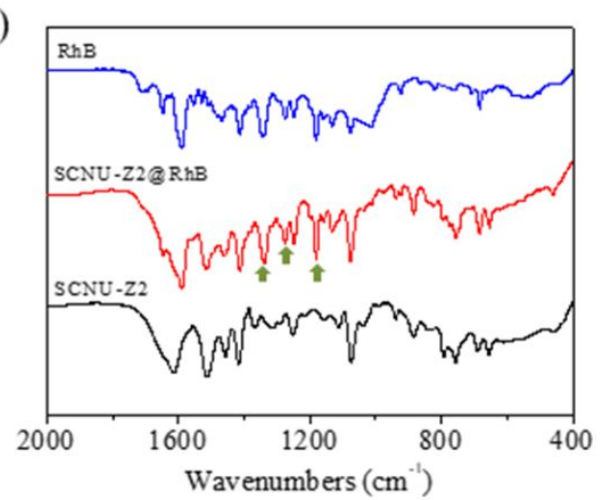

Figure 12. (a) the PXRD of SCNU-Z2, SCNU-Z2@MLB, SCNU-Z2@CV, and SCNU-Z2@RhB. IR spectroscopy of (b) MLB, SCNU-Z2 and SCNU-Z2@MLB, (c) CV, SCNU-Z2 and SCNU-Z2@CV, (d) RhB, SCNU-Z2 and SCNU-Z2@RhB.

(a)

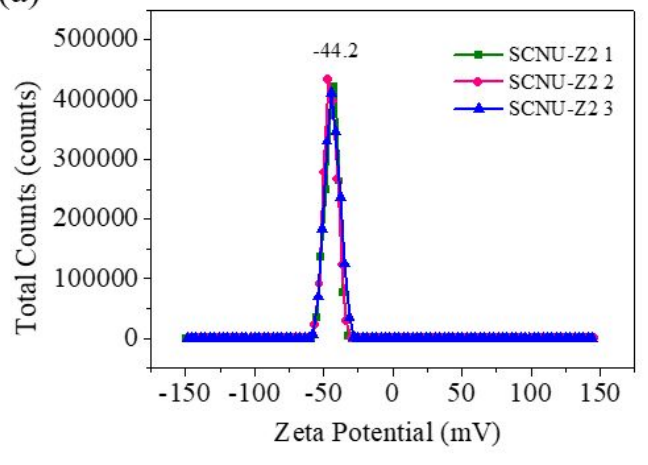

(b)

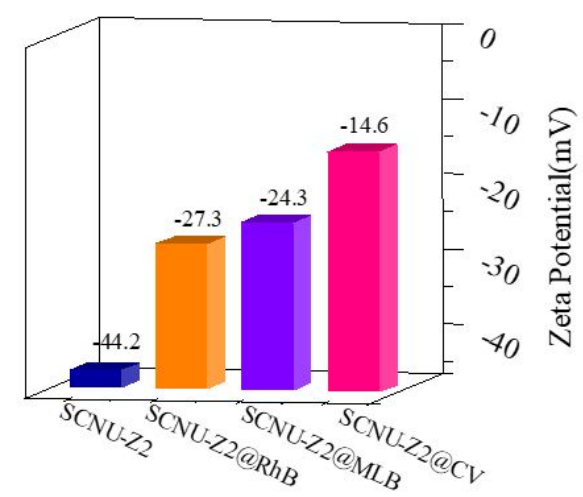

Figure S13. (a) The zeta potential of SCNU-Z2. (b) The comparison of zeta potential of SCNU-Z2,SCNU-Z2@MLB, SCNU-Z2@CV, and SCNU-Z2@RhB. 


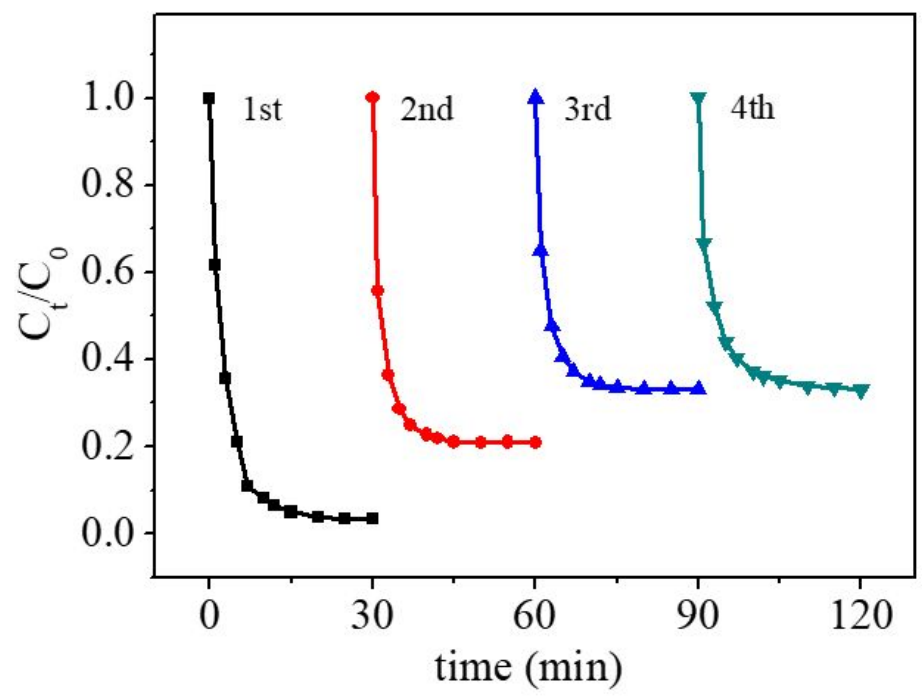

Figure S14. The degradation of $\mathrm{MB}$ in dark/SCNU-Z2 condition in recycling runs.

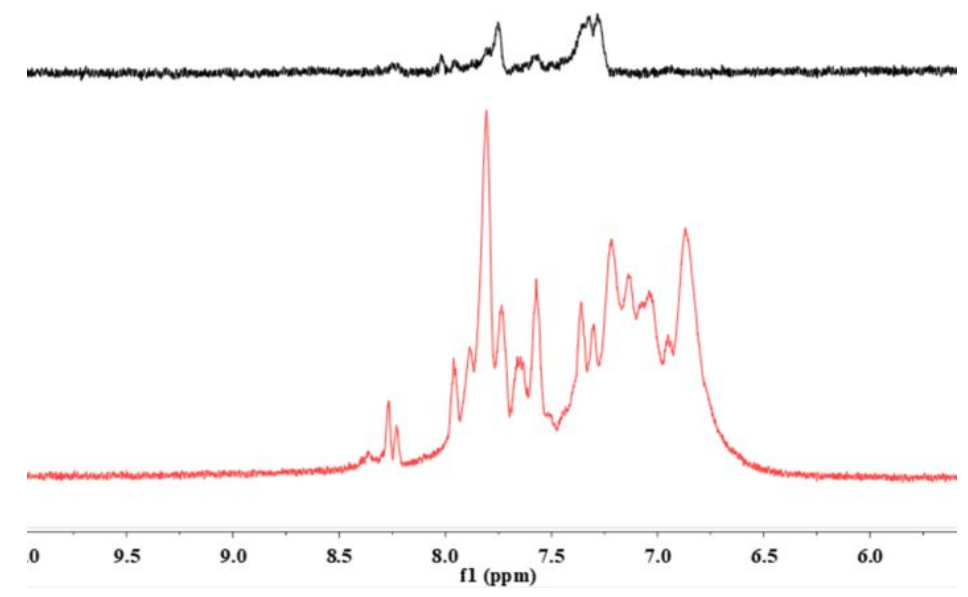

Figure S15. ${ }^{1} \mathrm{HNMR}$ spectra of MB solution before (below) and after (upper) adding SCNU-Z2. 


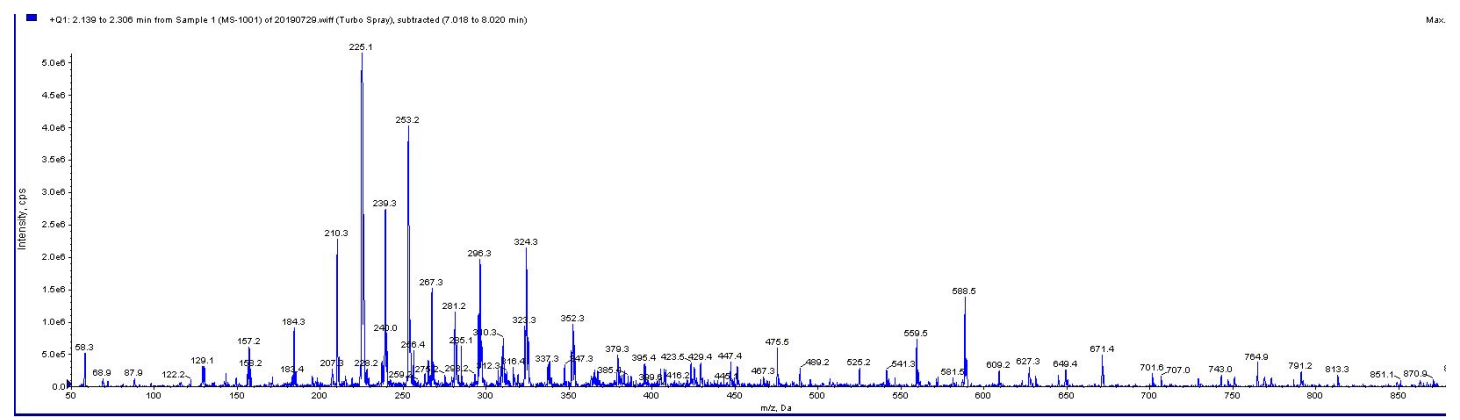

Figure S16. MS spectra of MB solution and after adding SCNU-Z2. 